\title{
Apolipoproteins in lipid transport, an impressionist view
}

\author{
D. Willem Erkelens
}

Department of Internal Medicine, University Hospital, Catharijnesingel 101, 3511 GV Utrecht, The Netherlands.

\section{Introduction}

The major function of the lipoproteins is to provide the organism with a transport system for triacylglycerol and cholesterol. This system appears to be both highly effective and dynamic in normal subjects. While about $150 \mathrm{~g}$ of fat per day are fully absorbed from the gut, the plasma triglyceride pool in the blood is approximately $3 \mathrm{~g}$ in the fasting state and does not exceed $12 \mathrm{~g}$ in the postabsorbtive state. About $1 \mathrm{~g} /$ day of cholesterol is produced in the liver and $0.2-0.5 \mathrm{~g}$ is absorbed from the gut, but the plasma pool is kept at a steady level under $6 \mathrm{~g}$. It is therefore understandable that minor abnormalities in the proteins that regulate lipid transport lead to grossly abnormal plasma lipid levels. These abnormal lipid levels in turn are associated with lipid accumulations at abnormal sites: the artery wall, macrophages, tendons, skin and various other tissues. This causes the clinical picture doctors observe, such as atherosclerosis, xanthomas, corneal opacifications and lipaemia retinalis.

Clinicians are used to the description of abnormal lipid transport in terms of the lipids proper, for example hypercholesterolaemia, hypertriglyceridaemia and combined hyperlipidaemia. These parameters can be measured easily and relatively accurately. Cholesterol and triglyceride are, however, innocent bystanders in lipoprotein disorders. We will therefore describe the transport disturbances in terms of the protein abnormalities of apolipoproteins, receptors, transfer proteins and enzymes. This enhances the pathophysiological understanding on the one hand and on the other provides arguments for measuring apolipoproteins in the assessment of atherosclerosis risk.

Correspondence: Professor D.W. Erkelens, M.D., This paper is based on the first 'Fellowship of Postgraduate Medicine' lecture, supported from the Davidson fund, which was given at the Eurotherapeutics III meeting organized by the European Association of Internal Medicine on 'Risk factors in Vascular Disease - Strategies for Treatment' held in Amsterdam 29 September to October 1st, 1988. The proceedings of the meeting will be published as a supplement to the Postgraduate Medical Journal.
This article is by no means a complete review of the literature; recently two excellent books have appeared with reviews of the different lipoprotein subjects. ${ }^{1,2}$ Rather, it is an impressionist picture of a rapidly developing scene.

\section{Protein functions in lipid transport}

The description which follows cannot be understood without a list of the lipoproteins involved (Table I). The functions of the apolipoprotein can be described in general as follows. They give a defined structure and size to the emulsified macromolecular complexes, which are lipoproteins [apo B for low density lipoprotein (LDL) apo A for high density lipoprotein (HDL)]. Some of them enable the lipoprotein to move through the cellular membrane from inside to outside [apo B48 for chylomicrons, apo B100 for very low density lipoprotein (VLDL)]. Some act as ligands to specific high affinity receptors and guide the lipoproteins to sites of catabolism (apo B100 to the apo B/E receptor, apo $E$ to the apo $E$ and apo $B / E$ receptor). Some are necessary cofactors for enzymes involved in lipid transport [apo AI for lecithin cholesterol acyltransferase (LCAT), apo CII for lipoprotein lipase (LPL)] or inhibitors of catabolic pathways (apo CIII for triglyceride rich particles such as chylomicrons and VLDL).

The enzymes involved in the intravascular compartment are lipoprotein lipase attached to the endothelial surface, which hydrolyses triacylglycerol from chylomicrons and VLDL, hepatic lipase, which probably hydrolyses triacylglycerol from intermediate density lipoprotein (IDL) and probably helps in converting HDL 2 to HDL3 by removing part of the phospholipids and cholesterol, ${ }^{3}$ and lecithin cholesterol acyl transferase which esterifies cholesterol in HDL particles. ${ }^{4}$

Proteins which promote neutral lipid exchange and/or transfer are called lipid transfer proteins. ${ }^{5}$

The liver cells and other tissues contain high affinity receptors for $\mathrm{LDL}$, the $\mathrm{B} / \mathrm{E}$ receptor or $\mathrm{LDL}$ receptor, ${ }^{6}$ 
Table I Lipoproteins

\begin{tabular}{|c|c|c|c|}
\hline Name & Description & $\begin{array}{l}\text { Structural } \\
\text { apoprotein }\end{array}$ & 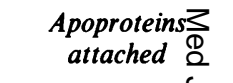 \\
\hline $\begin{array}{c}\text { chylomicron } \\
\text { chylomicron } \\
\text { remnant }\end{array}$ & $\begin{array}{l}\text { carries triglyceride from gut to adipose tissue, muscle, liver } \\
\text { chylo after intravenous hydrolysis of most triglyceride }\end{array}$ & $\begin{array}{l}\text { B48 } \\
\text { B48 }\end{array}$ & 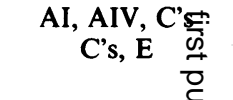 \\
\hline VLDL & carries triglyceride and cholesterol from liver to periphery & B100 & C's, E 흐 \\
\hline IDL & remnant of VLDL & B100 & \\
\hline LDL & carries cholesterol to liver and tissues & B100 & 6 \\
\hline HDL2 & $\begin{array}{l}\text { carries cholesterol from periphery to liver directly and } \\
\text { indirectly via other lipoproteins }\end{array}$ & AI, II & 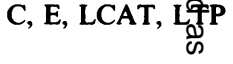 \\
\hline HDL3 & & AII, I & as HDL2 $\overrightarrow{0}$ \\
\hline
\end{tabular}

for remnants, the E receptor, ${ }^{7}$ and putatively for apo A the HDL receptor. ${ }^{8}$

Proteins can be described in molecular terms. The cDNA sequence, mRNA and amino acid sequence is known for most apoproteins, ${ }^{9}$ but is not discussed in this article. In order to better understand their individual role in lipoprotein transport we have coined an impressionist name for the most important ones (Table II). We will describe in the following section their function in more detail, and the consequences of abnormalities of each in man.

Table II Impressionist designation of apolipoproteins

\begin{tabular}{ll} 
apo A: & 'active alternator' \\
apo B: & 'big bulker' \\
apo C: & 'clever cleaner' \\
apo E: & 'enigmatic envoy' \\
\hline
\end{tabular}

\section{Apolipoprotein B, the 'big bulker' (Figure 1)}

Apo B is called 'big', because it is one of the largest proteins $(512,932$ daltons) known to circulate in the blood. ${ }^{10}$ It transports, as apo B48, the 'bulk' of triglyceride from the gut cells in which chylomicrons are formed, "via lymph and blood to adipose tissue, muscle and in the form of chylomicron remnants to the liver. Apo B48 appears not to bind to the B/E receptor. ${ }^{12}$ The removal of remnants therefore is dependant on apo $\mathrm{E}-\mathrm{E}$ receptor interaction. As apo B100 it carries first triglyceride in VLDL to the same LPL degradation sites as chylomicrons. ${ }^{13}$ Then the VLDL remnant, or IDL, partly binds to the apo B/E receptor and is transformed to LDL. Apo B100 is the sole protein of this particle. It binds to the apo $B / E$ or LDL receptor and is internalized.

One of its functions can be deduced from an experiment of nature, abetalipoproteinaemia, where either a deficient apo B is produced, or a posttranslational defect occurs. ${ }^{14}$ Triglyceride remains trapped inside the intestinal and liver cells. The blood is devoid of chylomicrons, VLDL and LDL. Oำ HDL is present to carry cholesterol. The triglycef de level is very low, except in the rare apo B100 deficiengcy where apo B48 is produced normally, ${ }^{15}$ or in chylorficron retention disease where chylomicrons are absodt, but apo B100 is normal. ${ }^{16}$ Clinical sequelae of the disease are predominantly due to vitamin $\mathrm{E}$ deficiency for which $\mathbf{L D L}$ is the principal carrier, and vitamio $\mathrm{A}$ deficiency for which chylomicrons are the carriers,

Overproduction of VLDL apo B100, probably due to disregulation of the apo $B$ regulator genes, is putative causal mechanism for familial combined hyperlipidaemia. ${ }^{17}$ This entity is the most freqgeofly encountered hyperlipidaemia in myocardial infaetion survivors, which underlines the importance of apo-B-aemia in the pathogenesis of atherosclerass. ${ }^{18}$ Family members have hyper-apo-B-aemia with eififer elevated levels of VLDL, LDL, or both.

Impaired removal of apo B100 due to deficienc the LDL receptor leads to familial hygercholesterolaemia, the entity most feared for 3 its atherogenesis at an early age and for its tendon xanthomas. ${ }^{19}$ It is possible that in the near future more genetic abnormalities of the apo B molecule itself yill

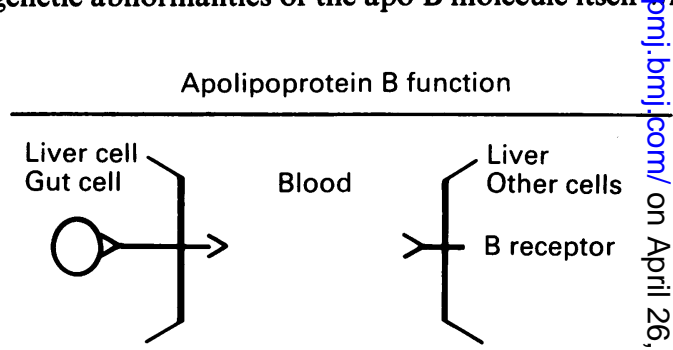

Structure

Transport

Receptor binding

స్ట

Figure 1 Apolipoprotein B, the 'big bulker', facilitates transport of chylomicrons and VLDL through the menbrane of the intestinal and liver cells. It gives structurefto the chylomicrons, VLDL, IDL and the apo B100\% of VLDL, IDL and LDL binds to the apo B/E or LDL receptor for internalization in liver and other cells. 
be described, which, if receptor binding domain(s) are included, will lead to the expression as familial hypercholesterolaemia.

In some instances glycoprotein (a) binds to apo B, thereby forming a lipoprotein called $\operatorname{Lp}(a) \cdot{ }^{20}$ The concentration of $\mathrm{Lp}(\mathrm{a})$ is independent of total $\mathrm{LDL}$ levels, but it is probably dependent on the difference in $\mathrm{Lp}(\mathrm{a})$ phenotypes. ${ }^{21}$ The presence of $\mathrm{Lp}(\mathrm{a})$ appears to be strongly associated with atherosclerosis. It is not known whether this is due to the similarity of glycoprotein (a) and plasminogen. ${ }^{22}$

\section{Apo A, the 'active alternator' (Figure 2)}

Apolipoprotein A-I is active because it is involved in both triglyceride and cholesterol transport and activates the essential enzyme for reverse cholesterol transport LCAT. It is an alternator because it enters the lymph as part of the chylomicron but rapidly switches to HDL. It probably forms new 'nascent' HDL particles by taking part of the chylomicron surface phospholipid with it. In doing so it facilitates apo CII transfer from HDL to chylomicrons, ${ }^{22}$ which in turn facilitates chylomicron triglyceride removal. When the detachment of apo A from chylomicrons is deficient as in Tangier disease, this results in both hypertriglyceridaemia and very low levels of HDL. ${ }^{24}$ Apo A is virtually undetectable in Tangier disease since it rapidly disappears with chylomicrons.

Further down the functional road, apo $A$ in nascent HDL picks up free cholesterol from cell surfaces. It is unknown at the present time whether free cholesterol transport from the cell surface to HDL is a random chemical process or depends on the presence of, for

\section{Apolipoprotein A function}

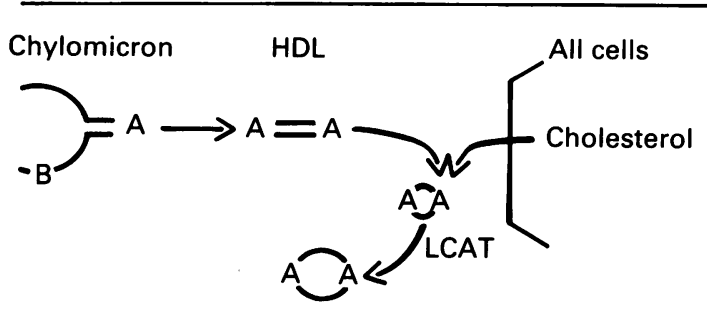

Facilitate Structure

Reverse cholesterol transport

LCAT activation

Figure 2 Apolipoprotein A, the 'active alternator', makes room on the chylomicron surface for apo CII binding, thereby facilitating catabolism. At the same time apo $\mathbf{A}$ forms new HDL which picks up cholesterol from cell surfaces (and atheromatous plaques?) and activates LCAT which results in cholesterol ester accumulation in mature HDL particles.
Apolipoprotein C function

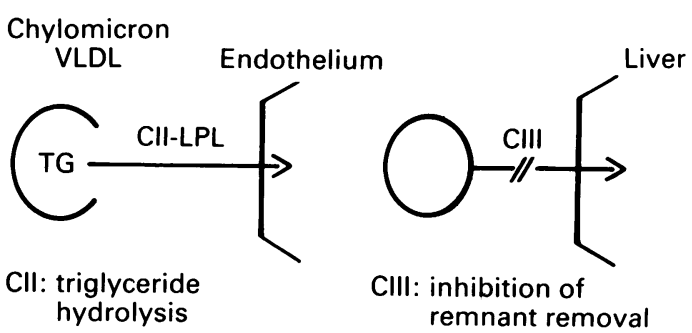

Figure 3 Apolipoprotein C, the 'clever cleaner', helps LPL in hydrolysing triglyceride from chylomicrons and VLDL as apo CII. Apo CIII inhibits remnant removal by the liver cells.

example, a sterol carrier protein. ${ }^{25}$ The cholesterol thus obtained is esterified by LCAT, which is activated by apo AI. The mature HDL particle carries the cholesterol to the liver, either directly by the action of hepatic lipase, ${ }^{3}$ or indirectly via chylomicron remnants, IDL, and VLDL. ${ }^{26}$ The cholesterol ester transfer from HDL to these particles is facilitated by one or more of the cholesterol ester transfer proteins (or lipid transfer proteins) and inhibited by a lipid transfer protein inhibitor. ${ }^{27}$ Thus, the so called reverse cholesterol transport pathway from cell, and perhaps from atherosclerotic plaques, ${ }^{28}$ to the liver is completed. The liver is the major site of excretion of cholesterol into the bile. The pathway is also called the centripetal cholesterol pathway, which assumes the liver to be the centre of the metabolic universe.

Overproduction, or underremoval, of apo A results in hyperalphalipoproteinaemia. This entity is also known as 'longevity syndrome' since high HDL (apo A) levels are a strong negative risk factor for atherosclerosis. ${ }^{29}$ Whether this epidemiological finding is indeed based on the activity of the reverse cholesterol transport pathway and not merely a reflection of a low VLDL state, remains to be established.

\section{Apo C, the 'clever cleaner' (Figure 3)}

Apo C clears the blood of chylomicron triglyceride, but it is clever in sharing this task with LPL and by only being necessary in minor amounts to do the job. ${ }^{30}$ Apo $\mathrm{C}$ is probably produced in the liver and enters the circulation as part of HDL or VLDL. In the plasma it resides in the HDL pool. When chylomicrons enter the lymph apo $\mathrm{C}$ is rapidly transferred to the particles, ${ }^{31}$ probably in exchange for apo $\mathrm{A}$, which makes space available on the chylomicron surface. ${ }^{32}$ The apo CII molecule has one part between the phospholipid molecules of the chylomicron surface monolayer and one part which binds to LPL, ${ }^{33}$ opening up, as it were, 
the chylomicron particle to the hydrolytic action of LPL. It is a necessary cofactor for LPL. When apo CII is totally absent, massive hypertriglyceridaemia ensues with prolonged circulating chylomicrons and VLDL. ${ }^{34}$ The clinical picture is not different from LPL deficiency. The very high triglyceride levels are associated with recurrent bouts of pancreatitis, lipaemia retinalis and sometimes eruptive xanthomas. The clever apo CII is only necessary in minute amounts to fully activate LPL. Heterozygous family members of apo CII deficient patients are normotriglyceridaemic. $^{35}$

Apo CIII is the clever counterpart of CII. In apo AI-CIII deficiency (both genes on the long arm of chromosome 11) the triglyceride level is very low. This probably is due to a lack of chylomicron remnant clearance inhibition by apo CIII. ${ }^{36}$ Some investigators have found low apo CII/CIII ratios in hypertriglyceridaemia and it may be that a low CII/CIII ratio of transferrable protein predisposes patients to develop secondary hypertriglyceridaemia when acquiring hypothyroidism, diabetes or kidney disease. ${ }^{37}$

\section{Apo E the 'enigmatic envoy' (Figure 4)}

Apo E seems to be sent out by the liver as an envoy to bring back as much cholesterol as it can from different sources. It retrieves the lost sons of triglyceride rich particles to carry their harvest of cholesterol obtained from the reverse cholesterol transport to the paternalistic liver. But it is enigmatic as well. It appears in different isoforms. ${ }^{38}$ Each individual has its phenotype, coded for by three alleles, $\in 2, \in 3$ and $\in 4$. The apo E2/E2 phenotype is associated with the relatively rare, atherogenic, familial dysbetalipoproteinaemia when VLDL and therefore IDL production is increased.$^{39}$ In general, however, the apo E2/E2 phenotype protects against atherosclerosis by causing low LDL levels. ${ }^{40}$

\section{Apolipoprotein E function}

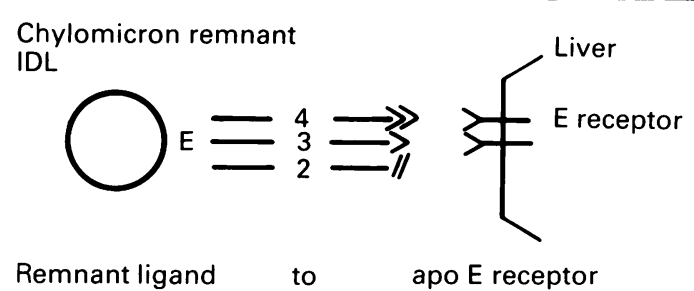

Figure 4 Apolipoprotein E, the 'enigmatic envoy', binds to chylomicron and VLDL remnants and on the other hand to the apo E receptor. Apo E4 does so with a higher affinity than apo E3, while apo E2 binds poorly to the receptor.
Let me explain. Apo $\mathrm{E}$ is excreted from the 1 ifer associated with HDL. It transfers to chylomicrons and VLDL during and after the process of LPL-mediated triglyceride hydrolysis. The resulting particifes, chylomicron remnants and VLDL remnants (IDL)are thus apo $\mathrm{E}$ rich. And apo $\mathrm{E}$ is the ligand to the apo $\mathrm{E}$ receptor. The affinity of each of the apo $E$ isoforms to the apo $\mathrm{E}$ receptor is different. Apo E4 binds best, \&po E3 a bit less and apo E2 insufficiently. ${ }^{40}$

The liver cell aims for homeostasis of its cholest level. Let us assume that it can get its cholesterol eiduner from LDL via the LDL receptor pathway or otherwise from remnants via the apo E receptor pathway. When an individual has the apo E4/E4 phenotype The cholesterol will be obtained mainly through the apd $\mathrm{E}$ receptor. The LDL receptor will be down-regulas d, and relatively high LDL levels are the result. Onghe other hand when the apo E2/E2 phenotype is present, the apo $\mathrm{E}$ receptor pathway will be inactive, the LDL receptor will be up-regulated and LDL will o be relatively low. The other phenotypes (E4/E3, E3/ Fe 3 , $E 4 / E 2, E 3 / E 2)$ will be in between. This is indeed exactly what is found within different populations, $\mathrm{E} 4 / \mathrm{E} 4$ is high in the cholesterol distribution and E2фE2 low. ${ }^{41}$ It may well explain genetically determined variations in LDL cholesterol levels, apart from ap B or apo B receptor abnormalities.

Low LDL levels are the rule in apo E2fE2 homozygosity. This is mainly due to inade्ergate catabolism of IDL to LDL. If an over-production of the IDL precursor VLDL is operative, as in faing combined hyperlipidaemia, alcohol use and diabes, an accumulation of IDL is the consequence. The is known as type III hyperlipidaemia, broad Feta disease, remnant removal disease or famqial dysbetalipoproteinaemia. The IDL are detecteक 5 as combined hyperlipidaemia and increased relațve cholesterol levels in the ultracentrifugal VLDL fraction.

Apo E phenotyping is now available by a relatively simple immuno-blotting technique for detection of these patients. ${ }^{42}$ The IDL particles are highly atherogenic and type III patients tend to have early severe atherosclerosis, particularly in the peripheral arteries, and pathognomonic palmar xanthomas. The abnormality rapidly responds to dietary measures or drugs which decrease VLDL production, such as the fibrates.

Recently apo E production has been describeduin other tissues than the liver, such as macrophages. ${ }^{43}$ The role of apo $\mathrm{E}$ in cholesterol transport from these cells remains to be clarified. Total apo E deficiency tas been described and adds to the enigmatic charactefof the protein..$^{44}$ Massive hypertriglyceridaemia in this entity may point to a function of apo E3 in triglyce removal from chylomicrons and VLDL. 


\section{LPL, HL, LCAT, CETP, the 'magnificent modulators'}

They are magnificent since deficiency of each results in grossly abnormal lipoproteins. They are modulators because they strongly change the composition of most lipoproteins.

LPL is a long molecule, attached to the luminal side of the endothelial cell. ${ }^{45}$ It keeps away the lipoprotein particle from the cell surface. Does it do so to protect the cell against lipid peroxidation products? It modifies the chylomicron to remnant and the VLDL to IDL. It is hormone dependent, specifically to insulin and probably to thyroxine. Its absence results in massive hyperchylomicronaemia (see apo CII deficiency). ${ }^{46}$

Hepatic lipase (HL) is less well-known, its function is not entirely clear. Some investigators have evidence to show that it not only hydrolyses triglyceride but phospholipids and cholesterol ester as well. ${ }^{3}$ It would thus modify HDL2 by removing part of its lipids to HDL3 and complete this arm of the reverse cholesterol transport pathway. Others have evidence that it is operative in the modification of IDL to $\mathrm{LDL}^{47} \mathrm{We}$ have described above that chylomicron and VLDL remnants are both handled by the liver in the same way. Actually chylomicron remnants containing apo B48 and apo $E$ are rapidly internalized by the liver and not converted to another particle.

VLDL remnants (IDL) containing apo B100 and apo E, on the contrary, are either internalized by the liver or bound to its surface and hence metabolized to LDL containing only apo B100. The choice between these two possibilities may be dependent on the size of the particle, and hepatic lipase may be the enzyme responsible for the conversion of the IDL to LDL.

LCAT was an enzyme without a disease to which relatively little attention was paid, until LCAT deficient patients were described..$^{48}$ They have a high level of unesterified cholesterol, a low level of esterified cholesterol and an abnormal composition of all lipoproteins, partly as a consequence of structural changes due to an imbalance in the phospholipid-free cholesterol ratio and partly to modifications in apolipoprotein binding. A large vesicular lipoprotein, LpX, is found in obstructive jaundice. ${ }^{49}$

Cholesteryl ester transfer protein (CETP) is a relatively new member of the lipid transport protein family. It facilitates exchange of neutral lipids between lipoproteins. For example cholesterol ester from HDL is avidly exchanged for triglyceride from chylomicrons and VLDL. ${ }^{26}$ This process may be elevating the cholesterol content of remnants. Differences in CETP activity have been described in hyperlipidaemia, high levels being associated with low HDL cholesterol and high VLDL + LDL cholesterol. ${ }^{50}$ The clinical significance of these proteins and their inhibitors remains to be established, although differences in lipoproteins between species have been explained in the view of different CETP activity. ${ }^{\text {s1 }}$

\section{Apolipoproteins and atherosclerosis}

The atherogenic lipoproteins are LDL, IDL, VLDL and possibly chylomicron remnants. All these lipoproteins have apo B as a common structural apolipoprotein. There is one apo B molecule per lipoprotein particle, while the cholesterol content varies. The total plasma apo B level, therefore, is an indication of the concentration of atherogenic particles. The 'antiatherogenic' lipoprotein is HDL, the major structural apolipoprotein of which is apo A. There are approximately two apo A molecules per HDL particle, so that the apo $A$ level is an indication of the number of anti-atherogenic particles in the circulation. The cholesterol content per particle also varies.

If cholesterol is present in both atherogenic and anti-atherogenic particles and in both in varying quantities, why do we measure cholesterol as a major risk indicator for atherosclerosis? Why do we not measure apolipoproteins B and A instead and calculate the apo B/A ratio? The major reason is probably that cholesterol measurement is and has been widely available by relatively well standardized methods. Large amounts of data can be easily accumulated and compared in prospective epidemiological studies to evaluate the risk predicting potential of the cholesterol level (and HDL cholesterol and triglyceride levels).

There is evidence, however, from a number of cross-sectional studies that apo B is a better indicator than cholesterol or even LDL cholesterol. ${ }^{18}$ In familial combined hyperlipidaemia, which is associated with atherosclerosis, apo B is elevated, while in familial hypertriglyceridaemia which is not associated with atherosclerosis, the apo B level is close to reference values. ${ }^{52}$

Since immunological methods for the assessment of both apo $B$ and apo $A$ levels (rocket immuno-electrophoresis, radial immuno-diffusion, immuno-nephelometry, ELISA) have become more widely available, it is to be expected that they will replace cholesterol, HDL cholesterol and triglyceride measurement as assessors of risk for atherosclerosis, both for populations and for the individual. Analysis of apo E isoforms and of $L p(a)$ will probably be added on a large scale. Proper standardization for the measurement of the apolipoproteins is urgently warranted. We may at some time in the future diagnose hyper-apo-Baemia or hypo-apo-A-aemia instead of hypercholesterolaemia and hypo-HDL-aemia.

It has been the purpose of this review to enhance the readers understanding of the intriguing faculties of the apolipoproteins and of how intricate a system nature 
has designed for lipid transport. The practical advantage of this knowledge may be better advice and

\section{References}

1. Shepherd, J. (ed.) Lipoprotein metabolism. In: Bailliere's Clinical Endocrinology and Metabolism, Vol. 1. Baillière Tindall, London, 1987, pp. 495-775.

2. Gotto, JR, A.M. Plasma lipoproteins. In: Neuberger, A., Van Deenen, L.L.M. (eds) New Comprehensive Biochemistry, Vol. 14. Elsevier, Amsterdam, 1987, pp. 1-405.

3. Jansen, H. \& Hulsmann, W.C. Enzymology and physiological role of hepatic lipase. Biochem Soc Trans 1985, 13: 24-26.

4. Glomset, J.A. Physiological role of lecithin-cholesterol acyltransferase. Am J Clin Nutr 1970, 23: 1129-1136.

5. Zilversmit, P.B. Lipid transfer proteins. J Lipid Res 1984, 25: $1563-1566$.

6. Brown, M.S. Kovanan, P.T. \& Goldstein, J.L. Regulation of plasma cholesterol by lipoprotein receptors. Science 1981, 212: 628-635.

7. Mahley, R.W., Hui, D.Y., Innerarty, T.L. \& Weisgraber, K.H. Two independent lipoprotein receptors on hepatic membranes of dog, swine and man. J Clin Invest 1981, 68: 1197-1206.

8. Biesbroeck, R. Oram, J.F., Albers, J.J. \& Bierman, E.L. Specific high affinity binding of HDL to cultured human skin fibroblasts and arterial smooth muscle cells. $J$ Clin Invest 1983, 71: 525-539.

9. Breslow, J.L. Lipoprotein genetics and molecular biology. In: Gotto, JR, A.M. (ed.). Plasma Lipoproteins. Elsevier, Amsterdam 1987, pp. 359-397.

10. Yang, C-Y, Chan, L. \& Gotto, JR, A.M. The complete structures of human apolipoprotein B-100 and its messenger RNA. In: Gotto, JR, A.M. (ed.) Plasma Lipoproteins. Elsevier, Amsterdam, 1987, pp. 77-93.

11. Kane, J.P. Hardman, D.A. \& Paulus, H.E. Heterogeneity of apolipoprotein B: Isolation of a new species from human chylomicrons. Proc Natl Acad Sci (USA) 1980, 77: 2465-2469.

12. Hui, D.Y., Innerarity, T.L. Milne, R.W. Marcel, Y.L. \& Mahley, R.W. Binding of chylomicrons remnants and beta-very low density lipoproteins to hepatic and extrahepatic lipoprotein receptors. J Biol Chem 1984, 259: 15060-15068.

13. Brunzell, J.P., Hazzard, W.R. Porte, JR, D. \& Bierman, E.L. Evidence for a common saturable triglyceride removal mechanism for chylomicrons and VLDL in man. J Clin Invest 1973, 52: 1578-1785.

14. Dullaart, R.P.F., Speelberg, B. Schuurman, et al. Epitopes of apolipoproteins B-100 and B-48 in both liver and intestine. Defective expression in recessive abetalipoproteinemia. J Clin Invest 1986, 74: 1397-1404.

15. Malloy, M.J., Kane, J.P., Harman, D.A., Hamilton, R.L. \& Dalal, K.B. Normotriglyceridemic abetalipoproteinemia, absence of the B-100 apolipoprotein. J Clin Invest 1981, 67: 1441-1450.

16. Levy, E., Marcel, Y.L., Deckelbaum, R.J. et al. Intestinal apo B synthesis, lipids, and lipoproteins in chylomicron retention disease. J Lipid Res 1987, 28: 1263-1274. treatment for patients who run a high risk fow atherosclerosis.
17. Goldstein, J.L., Schrott, H.G., Hazzard, W.R., Bierma稆 E.L. \& Motulsky, A.R. Hyperlipidemia in coronar heart disease. Genetic analysis and delineation of a netf inherited disorder: combined hyperlipidemia. $\mathrm{J} C \mathrm{Cl}$ Invest 1973, 52: 1544-1568.

18. Sniderman, A.D., Wolfson, C. Teng, B. et al. Associatio of hyperapobetalipoproteinemia with endogenous hypertriglyceridemia and atherosclerosis. Ann Int Medt 1982, 97: 833-839.

19. Goldstein, J.L. \& Brown, M.S. The low density lipopro tein receptor pathway and its relation to atherosclerosio Ann Rev Biochem 1977, 46: 897-930.

20. Morrisett, J.D., Guyton, I.R., Gaubatz, J.W. \& Gottio $J_{R}$, A.M. Lipoprotein (a): structure, metabolism and epidemiology. In: Gotto, JR, A.M. (ed.) Plasma Lipopro teins. Elsevier, Amsterdam 1987, pp. 129-152.

21. Gaubatz, J.W., Heidemann, C., Gotto, JR, A.M. Môํㄱ risett, J.D. \& Dahlen, G.H. Human plasma lipoprotein (a). Structural properties. J Biol Chem 1983, 258. $4582-4589$.

22. Brown, M.S. \& Goldstein, J.L. Plasma lipoprotein\$ Teaching old dogmas new tricks. Nature 1987, 336: 113-115.

23. Erkelens, D.W., Chen, C., Mitchell, C.D. \& Glomgę J.A. Studies on the interaction between apolipoproteinis $\mathrm{A}$ and $\mathrm{C}$ and triacylglycerol rich particles. Biociiro Biophys Acta 1981, 665: 221-233.

24. Herbert, P.N., Assman, C., Gotto, JR, A.M. \& Fredrick son, D.S. Familial lipoprotein deficiency (abetalipopros teinemia and Tangier disease). In: Stanbury, J.B., Wijn gaarden, J.B., Fredrickson, D.S., Goldstein, J.L. \& Brown, M.S. (eds) The Metabolic Base of Inherite Disease. McGraw-Hill, New York 1982, pp. 589-621.

25. Westerman, J. \& Wirtz, K.W.A. The primary structure of the non-specific lipid transfer protein (sterol carrier 23. from bovine liver. Biochem Biophys Res Commun 1985 127: 333-338.

26. Dullaart, R.P.F., Groener, J.E.M. \& Erkelens, D.W옹 Effect of the composition of very low and low density lipoproteins on the rate of cholesterylester transfer fror high density lipoproteins in man, studies in vitro. Eur $\$$ Clin Invest 1987, 17: 241 - 248.

27. Son, Y.C. \& Zilversmit, D.B. Purification and characterization of human plasma proteins that inhibit transfer activities. Biochim Biophys Acta 1984, 794: 473-480.

28. Small, D. Progression and regression of atherosclerotiou lesions. Arteriosclerosis 1988, 8: 103-129.

29. Gofman, J.W., Young, W. \& Tandy, R. Ischemic hear今 disease, atherosclerosis and longevity. Circulation 1960 34: 679-697.

30. Fielding, C.J. \& Fielding, P.E. Chylomicron protein content and the rate of lipoprotein lipase activity. J Lipie Res 1976, 17: 419-423.

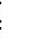

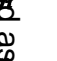


31. Erkelens, D.W., Brunzell, J.D. \& Bierman, E.L. Availability of apolipoprotein CII in relation to the maximal removal capacity for an infused triglyceride emulsion in man. Metabolism 1979, 28: 495-501.

32. Erkelens, D.W. \& Mocking, J.A.K. The effect of apolipoprotein $\mathrm{A}$ on in vitro apolipoprotein $\mathrm{C}$ binding and in vivo removal of artificial triacylglycerol rich particles. Metabolism 1985, 34: 222-226.

33. Smith, L.C. \& Pownall, H.J. Lipoprotein lipase activation by apolipoprotein CII. In: Borgström, B. \& Broekman, H.L. (eds). Lipases. Elsevier, Amsterdam, 1984, pp. 263-305.

34. Breckenridge, W.C., Little, J.A., Steiner, G., Chow, A.C. \& Poapst, M. Apolipoprotein CII deficiency. N Engl J Med 1978, 298: 1265-1273.

35. Miller, N.E., Rao, S.N., Alaupovic, P. et al. Familial apolipoproteins and apolipoproteins in heterozygous and homozygous subjects and the effects of plasma infusion. Eur J Clin Invest 1981, 11: 69-76.

36. Van Berkel, T.J.C., Kruijt, J.K., Scheek, L.M. \& Groot, P.H.E. Effect of apolipoproteins $\mathrm{E}$ and CIII on the interaction of chylomicrons with parenchymal and nonparenchymal cells from rat liver. Biochem $J$ 1983, 216: $71-80$.

37. Erkelens, D.W. \& Mocking, J.A.J. The CII/CIII ratio of transferable apolipoprotein in primary and secondary hypertriglyceridemia. Clin Chim Acta 1982, 121: 59-65.

38. Utermann, G., Hees, M. \& Steinmetz, A. Polymorphism of apolipoprotein E and occurrence of dysbetalipoproteinemia in man. Nature 1977, 269: 604-607.

39. Utermann, G., Vogelberg, K.H., Steinmetz, A. et al. Polymorphism of apolipoprotein E II. Genetics of hyperlipoproteinemia type III. Clin Genet 1979, 15: 37-62.

40. Weisgraber, K.H., Innerarity, T.L. \& Mahley, R.W. Abnormal lipoprotein binding activity of the human $\mathrm{E}$ apoprotein due to cysteine-arginine interchange at a simple site. J Biol Chem 1982, 257: 2518-2521.

41. Utermann, G. Apolipoprotein E polymorphism in health and disease. Am Heart $J$ 1987, 113: 433-440.

42. Havekes, L.M., De Knijff, P., Beisiegel, U., Havinga, J., Smit, M. \& Klasen, E. A rapid micromethod for apolipoprotein E phenotyping directly in serum. J Lipid Res 1987, 28: 455-463.
43. Takagi, Y., Dyer, C.A. \& Curtiss, L.K. Plateletenhanced apolipoprotein $\mathrm{E}$ production by human macrophages: a possible role in atherosclerosis. $J$ Lipid Res 1988, 29: 859-867.

44. Ghiselli, G., Schaefer, E.J., Gascon, P. \& Brewer, H.B. Apolipoprotein E deficiency. Science 1981, 214: 1239-1241.

45. Garfinkel, A.S. \& Schotz, M.C. Lipoprotein lipase. In: Gotto, JR, A.M. (ed.) Plasma Lipoproteins. Elsevier, Amsterdam, 1987, pp. 335-357.

46. Havel, R.J. \& Gordon, R.S. Idiopathic hyperlipidemia: metabolic studies in an affected family. J Clin Invest 1960 , 39: $1777-1790$.

47. Taskinen, M.R. \& Kuusi, T. Enzymes involved in triglyceride hydrolysis. Bailliere's Clinical and Endocrinological Metabolism, Vol. 1. Baillière Tindall, London, 1987, pp. 639-666.

48. Glomset, J.A. The plasma lecithin: cholesterol acyltransferase reaction. J Lipid Res 1968, 9: 155-167.

49. Glomset, J.A., Norum, K.R. \& Gjone, E. Familial lecithin: cholesterol acyltransferase deficiency. In: Stanbury, J.B., Wijngaarden, J.B. Fredrickson, D.S., Goldstein, J.L. \& Brown, M.S. (eds) The Metabolic Base of Inherited Disease, 5th edition. McGraw-Hill, New York, 1983, pp. 643-654.

50. Groener, J.E.M., Van Rozen, A.E. \& Erkelens, D.W. Cholesteryl ester transfer activity, localization and role in distribution of cholesteryl ester over lipoproteins in man. Atherosclerosis 1984, 50: $261-271$.

51. Ha, Y.C. \& Barter, P.J. Differences in plasma cholesteryl ester transfer activity in sixteen vertebrate species. Comp Biochem Physiol 1982, 71B: 265-269.

52. Brunzell, J.D., Albers, J.J., Chait, A., Grundy, S.M., Grozek, E. \& McDonald, G.B. Plasma lipoproteins in familial combined hyperlipidemia and monogenic familial hypertriglyceridemia. J Lipid Res 1983, 24: $147-155$. 